\title{
Erratum
}

\section{On the Algebraic Structure of Link-Diagrams on a 2-Dimensional Surface}

\section{Paolo Cotta-Ramusino ${ }^{1}$ and Maurizio Rinaldi ${ }^{2}$}

1 Universita di Milano, Milano, Italy

${ }^{2}$ Harvard University, Cambridge MA 02138, USA

Commun. Math. Phys. 138, 137 (1991)

Fig. 11 has been incorrectly reproduced. Here is the correct figure:
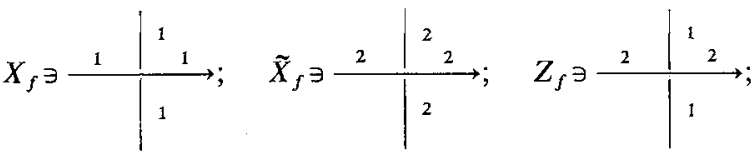

Fig. 11
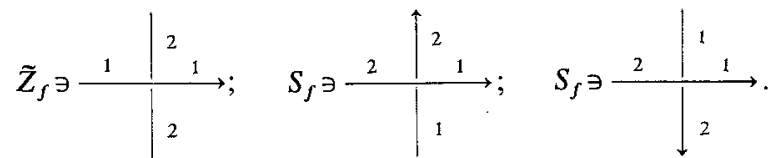

Communicated by A. Jaffe 